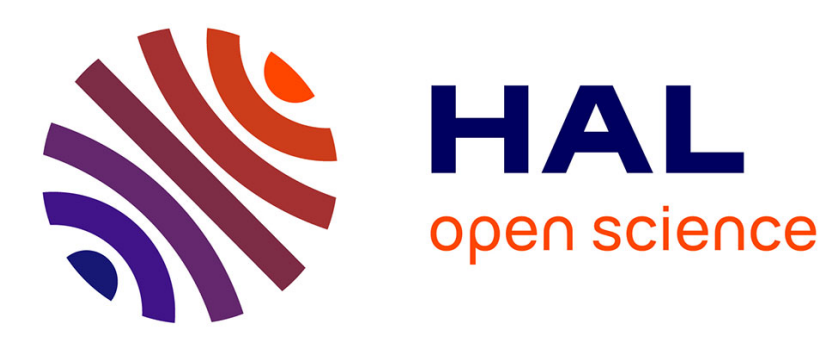

\title{
MOF-Based Membrane Encapsulated ZnO Nanowires for Enhanced Gas Sensor Selectivity
}

Martin Drobek, Jae-Hun Kim, Mikhael Bechelany, Cyril Vallicari, Anne Julbe, Sang Sub Kim

\section{To cite this version:}

Martin Drobek, Jae-Hun Kim, Mikhael Bechelany, Cyril Vallicari, Anne Julbe, et al.. MOF-Based Membrane Encapsulated ZnO Nanowires for Enhanced Gas Sensor Selectivity. ACS Applied Materials \& Interfaces, 2016, 8 (13), pp.8323 - 8328. 10.1021/acsami.5b12062 . hal-01677978

\section{HAL Id: hal-01677978 \\ https://hal.umontpellier.fr/hal-01677978}

Submitted on 7 Jul 2021

HAL is a multi-disciplinary open access archive for the deposit and dissemination of scientific research documents, whether they are published or not. The documents may come from teaching and research institutions in France or abroad, or from public or private research centers.
L'archive ouverte pluridisciplinaire HAL, est destinée au dépôt et à la diffusion de documents scientifiques de niveau recherche, publiés ou non, émanant des établissements d'enseignement et de recherche français ou étrangers, des laboratoires publics ou privés. 


\section{MOF-based membrane encapsulated $\mathrm{ZnO}$ nanowires for}

\section{enhanced gas sensor selectivity}

Martin Drobek ${ }^{l \pm}$, Jae-Hun Kim ${ }^{2 \pm}$, Mikhael Bechelany $*^{1}$, Cyril Vallicari ${ }^{1}$, Anne Julbe ${ }^{1}$, Sang Sub Kim $*^{2}$

${ }^{1}$ Institut Européen des Membranes, UMR 5635, Université de Montpellier, ENSCM, CNRS, Place Eugène

Bataillon, F-34095 Montpellier cedex 5, France

${ }^{2}$ Department of Materials Science and Engineering, Inha University, Incheon 402-751, Republic of Korea

${ }^{ \pm}$These 2 authors participated to this work equally

*corresponding authors:

Mikhael Bechelany: mikhael.bechelany@univ-montp2.fr, phone: +33467149167 , Fax: +33467149119

Sang Sub Kim:sangsub@inha.ac.kr ,

phone: +82328607546 , Fax: +82328625546

KEYWORDS. ZnO, nanowires, ZIF-8 membrane, encapsulation, gas sensing

\section{ABSTRACT}

Gas sensors are of a great interest for applications including toxic or explosive gases detection in both in-house and industrial environments, air quality monitoring, medical diagnostics or control of food/cosmetic properties. In the area of semiconductor metal oxides (SMOs)-based sensors, a lot of effort has been devoted to improve the sensing characteristics. In this work, we report on a general methodology for improving the selectivity of SMOx nanowires sensors, based on the coverage of $\mathrm{ZnO}$ nanowires with a thin $\mathrm{ZIF}-8$ molecular sieve membrane. The optimized ZnO@ZIF-8-based nanocomposite sensor shows markedly selective response to $\mathrm{H}_{2}$ in comparison with the pristine $\mathrm{ZnO}$ nanowires sensor, while 
showing the negligible sensing response to $\mathrm{C}_{7} \mathrm{H}_{8}$ and $\mathrm{C}_{6} \mathrm{H}_{6}$. This original MOF-membrane encapsulation strategy applied to nanowires sensor architecture pave the way for other complex 3D-architectures and various types of applications requiring either gas or ion selectivity, such as biosensors, photo(catalysts) and electrodes.

Gas sensors represent a huge market that nowadays exceeds 2.5 billion dollars, in which semiconductor oxide materials contribute for more than $20 \% .^{1}$ The driving applications include detection of toxic or explosive gases in industrial environments, in-house measurements of dangerous gases, air quality and greenhouse gas monitoring ${ }^{2}$, alongside with emerging applications in medical diagnostics ${ }^{3}$ and food/cosmetic quality control ${ }^{4}$. The sensing mechanism involves the adsorption of gases on the surface of the functional oxide material that causes a change of its electrical conductivity. ${ }^{5}$ In addition to the measurement of electrical conductivity variation, gas sensing could be realized by measuring the change in capacitance, work function, mass, optical characteristics or reaction energy released by the gas/solid interactions. Acoustic and calorimetric methods are also possible options. ${ }^{6}$ Indeed, the sensors surface characteristics such as composition, crystalline structure, morphology, and microstructure (roughness, porosity, grain size, etc...) are crucial parameters for optimal sensing response. These parameters impact on sensor properties: $i$ ) sensitivity, ii) selectivity, iii) response and recovery times but also on the stability of the sensing material over time.

For semiconductor metal oxides (SMOs)-based sensors, the selectivity is intrinsically scarce and strong efforts were recently devoted to improve both sensor response and selectivity ${ }^{7-9}$. Typical approaches for improving sensitivity include the development of nanostructured materials with high effective surface areas, aiming to increase the number of gas adsorption sites. ${ }^{10}$ On the other hand, functionalization of sensor materials with special catalytic elements including noble metals or metal oxides is often used to improve the selectivity. Composing 
"sensor arrays" with zones providing different functional properties and whose response can be treated comparatively is a potential option to achieve the required selectivity in gas mixture atmosphere. Only rare examples of attractive gas sensing properties have been reported for organic inorganic-hybrid layers. Original nanoporous organotin hybrid thin film has been recently developed by self-assembling, providing unexpected selectivity for $\mathrm{H}_{2}$ gas sensing at moderate temperature ${ }^{11}$. The best selectivity to $\mathrm{H}_{2}$ was observed at $150^{\circ} \mathrm{C}$ with films that do not display any response to $\mathrm{CO} .^{12}$

In the area of novel functional materials, our research group recently developed an innovative approach for the synthesis of ZIF-8-based nanocomposite membranes applying so called "reactive seeding" approach. ${ }^{13}$ The method involves the Atomic Layer Deposition (ALD) of $\mathrm{ZnO}$ thin films and their subsequent conversion to $\mathrm{ZIF}-8$ using a 2methylimidazole/methanol solution under solvothermal conditions. ZIFs structures (Zeolitic Imidazolate Frameworks) represent a sub-family of Metal-Organic Frameworks (MOFs) which feature ultrahigh porosity, structural and chemical tunability together with structural flexibility and huge equivalent internal surface areas. The unique attributes of MOFs can be advantageously exploited for a large variety of applications including catalysis, gas separation and storage, nonlinear optics, light-harvesting, drug delivery, and more recently sensory applications ${ }^{14}$ and the protection of sensing devices with MOF-based selective barriers. ${ }^{14-15}$ Indeed the highly porous structures of MOFs enhance species uptake (pre-concentration) and the well-defined pore structures of MOFs provides molecular sieving. ${ }^{13}$ These two effects are expected to enhance both sensor response sensitivity (preconcentration effect) and selectivity (size/shape exclusion effect). Taking advantage of the unique properties of ZIF-8 material, we proposed in this work a very promising synthesis strategy for improving the selectivity of SMOx nanowire gas sensors. In order to reach the objective, an original design of the functional material composed of $\mathrm{ZnO}$ nanowires ( $\mathrm{ZnO} \mathrm{NWs}$ ) homogeneously encapsulated in 
a crystalline ZIF-8 selective layer has been achieved. The method relies on the utilization of $\mathrm{ZnO} \mathrm{NWs}$ as a unique source of zinc which is subsequently used for growing a thin ZIF-8 layer on the nanowires surface. In fact, this method enables homogeneous coverage of $\mathrm{ZnO}$ NWs with a ZIF-8 selective barrier (membrane) with high equivalent specific surface area and molecular sieving properties. Application of such an approach, targeting enhanced gas sensing selectivity thanks to a synergic effect of $\mathrm{ZnO}$ and $\mathrm{ZIF}-8$ in the specifically designed nanocomposite ZnO@ZIF-8 material has never been reported in the literature, yet. As shown, thanks to the molecular sieving effect of the thin ZIF-8 membrane, the ZIF-8 encapsulated $\mathrm{ZnO}$ nanowires-based sensor exhibits greatly improved selectivity for $\mathrm{H}_{2}$ in comparison with the pristine $\mathrm{ZnO} \mathrm{NWs}$ sensor. Because $\mathrm{H}_{2}$ is a clean, efficient promising candidate for renewable energy sources, its production, transportation and storage are key processing steps which must be performed safely. Accordingly, the accurate detection of $\mathrm{H}_{2}$ gas leaks is crucial and the novel approach developed in this work could be relevant for such strategic applications.

The present approach for improving the gas sensing selectivity of $\mathrm{ZnO}$ NWs by a controlled encapsulation of ZnO NWs with a MOF-based membrane involves two key steps: (i) growth of $\mathrm{ZnO} \mathrm{NWs}$ on the sensor support; and (ii) controlled conversion of the $\mathrm{ZnO}$ NWs surface, in order to grow a thin ZIF-8 selective barrier covering the ZnO NWs. (Figure 1 and Supporting information S1) 


\section{Growth of networked $\mathrm{ZnO}$ nanowires}
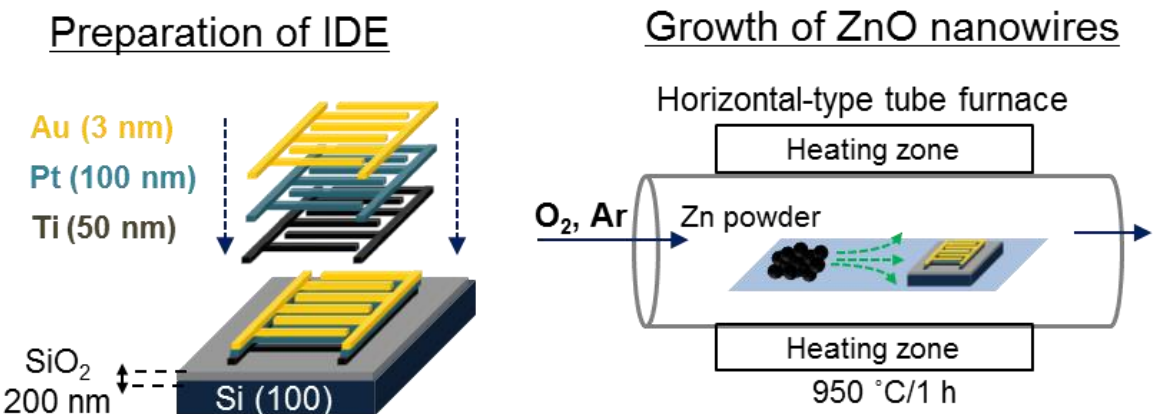

Cross-sectional view

$200 \mathrm{~nm}$

Si (100)

\section{Synthesis of ZIF-membrane encapsulated $\mathrm{ZnO}$ nanowires}

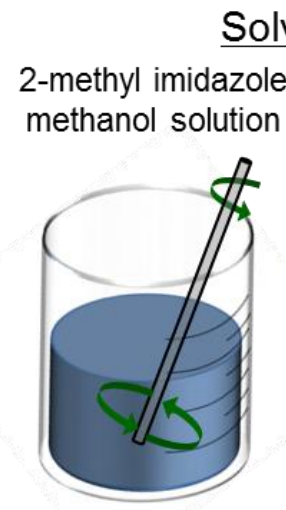

Stirring for $10 \mathrm{~min}$

2-methyl imidazole
Solvothermal treatment methanol solution

\section{Stiring for 10 min}

Stiring for 10 min

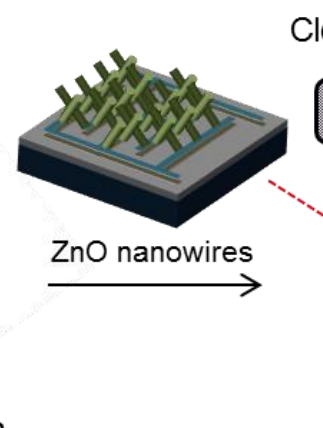

Closed pressure vessel

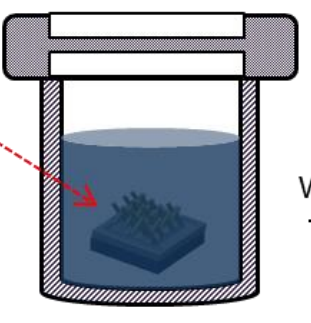

$100{ }^{\circ} \mathrm{C} / 24 \mathrm{~h}$ in oven
ZnO@ZIF-8 composite nanowires
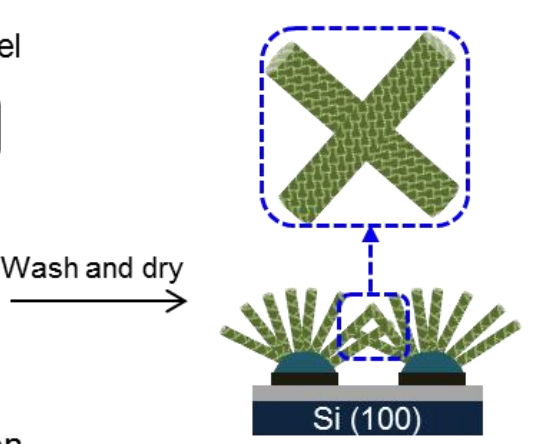

Figure 1. Schematic of the synthesis steps yielding the ZIF-membrane encapsulated ZnO nanowires (ZnO@ZIF-8 NWs).

The synthesis protocol has been optimized in order to get a maximal selectivity in gas sensing response for $\mathrm{H}_{2}$ in the presence of $\mathrm{C}_{6} \mathrm{H}_{6}$ and $\mathrm{C}_{7} \mathrm{H}_{8}$. The characteristics of both pristine $\mathrm{ZnO}$ NWs and the derived $\mathrm{ZnO} @ \mathrm{ZIF}-8$ nanocomposites have been investigated. Gas sensing experiments have been performed with $\mathrm{C}_{6} \mathrm{H}_{6}, \mathrm{C}_{7} \mathrm{H}_{8}$ and $\mathrm{H}_{2}$ single gases.

Figure 2a (typical plane-view FESEM image) clearly shows the microstructure of the $\mathrm{ZnO}$ NWs 3-D network connecting neighboring electrode pads on the gas sensor support. This 
nanowire-nanowire junction provides the electrical pathway whose resistance changes as a function of the concentration and type of surrounding molecules. The high resolution SEM image shown in the Figure 1 reveals the networking design of the $\mathrm{ZnO}$ nanowires more evidently. The typical diameter of the $\mathrm{ZnO}$ NWs was $\sim 85 \mathrm{~nm}$, with the length reaching up to $25 \mu \mathrm{m}$.

The encapsulated ZnO@ZIF-8 NWs have been prepared by conversion of the pristine $\mathrm{ZnO}$ NWs surface in contact with a methanolic solution of 2-methylimidazole (2-mim) at $100{ }^{\circ} \mathrm{C}$ for $24 \mathrm{~h}$. Different concentrations of the organic linker in the reaction solution have been tested in order to examine the impact on the $\mathrm{ZnO}$ NWs conversion degree. The goal was to grow a continuous $\mathrm{ZIF}-8$ layer on the $\mathrm{ZnO} \mathrm{NWs}$ while maintain the interconnected $\mathrm{ZnO}$ network on the sensor support. Indeed, under optimal reaction conditions with 2-mim concentration of $10 \mathrm{wt} \%$, a ZIF-8 layer was grown on the $\mathrm{ZnO}$ nanowires, covering their entire surface. $\mathrm{ZnO}$ conversion to $\mathrm{ZIF}-8$ occurs via a coordination reaction between $\mathrm{Zn}^{2+}$ cations ( $\mathrm{ZnO}$ top-surface) and imidazolium anions $\left(\mathrm{mim}^{-}\right)$in the solution. Assuming a right balance between the dissolution and coordination rate of $\mathrm{Zn}^{2+}$, no metal loss by leaching is expected during the solvothermal synthesis. Considering the low dissociation rate of $\mathrm{ZnO}$ into $\mathrm{Zn}^{2+}$ under the gentle solvothermal conditions applied, relatively slow conversion rates were involved with a limited (only top-surface) conversion of $\mathrm{ZnO}$ to $\mathrm{ZIF}-8$. These optimized conditions allow conserving the initial gas sensor architecture, with the interconnected $\mathrm{ZnO}$ NWs deposited on the sensor support. Both ZIF-8 and ZnO crystalline phases were found to co-exist in the ZnO@ZIF-8 samples, as confirmed in Figure S1 by the characteristic GIXRD lines of both $\mathrm{ZIF}-8\left(2 \Theta=7.3^{\circ}(011), 10.4^{\circ}(200), 12.7^{\circ}(112), 18.0^{\circ}(222)\right)$ and $\mathrm{ZnO}(2 \Theta=$ $\left.31.7^{\circ}(100), 34.4^{\circ}(002), 36.2^{\circ}(101)\right)$. The success of the partial conversion of $\mathrm{ZnO}$ NWs to ZnO@ZIF-8 composite materials has been attested as well by XPS analysis (Table S1). Indeed the binding energies of $\mathrm{C} 1 \mathrm{~s}, \mathrm{O} 1 \mathrm{~s}, \mathrm{Zn2p} 3$, and N1s peaks observed at 283.12, 530, 
1020.05 and $397.18 \mathrm{eV}$ confirm the presence of both $\mathrm{ZIF}-8$ and $\mathrm{ZnO}$ in the samples. The global EDX mapping measurements of the whole gas sensor surface revealed uniform distribution of nitrogen and carbon on the $\mathrm{ZnO} \mathrm{NWs}$, confirming the formation of $\mathrm{ZIF}-8$ material (Figure S2 and Table S2). This observation is in line with our parallel investigations of ZIF-8 growth on PAN electrospun nanofibers covered by ALD of ZnO thin films. ${ }^{14}$ This previous work demonstrated the feasibility and robustness of the proposed synthesis strategy for growing MOF-based materials from a metal oxide surface used as the sole metal source. ${ }^{16}$ FESEM images of the $\mathrm{ZnO} \mathrm{NWs}$ after the solvothermal treatment in the presence of 2-mim (Figure 2b) clearly confirms the preservation of the 3D interwoven nanofibers mat architecture on the sensor support. Due to the small size of $\mathrm{ZnO}$ nanofibers before and after the solvothermal treatment, it was very tricky to determine the characteristics (thickness, mean crystal size...) of the grown encapsulating ZIF-8 layer by using a classical SEM apparatus. From a closer examination of the composite material it could be concluded that, after the solvothermal treatment, the $\mathrm{ZnO}$ NWs seem to be more stacked together in a form of plait-like structures (Figure 2b), making bridge connections between the electrode pads.

In order to get a further insight into the ZnO@ZIF-8 NWs microstructure, HRTEM observations have been conducted on the as-prepared samples. The HRTEM analysis (TEM imaging and STEM/EDX analysis) confirmed that the nanowires scratched out from the sensor support are composed of a $\mathrm{ZnO}$ fiber core encapsulated in a $\mathrm{ZIF}-8$ nanomembrane shell. In fact the STEM/EDX mapping shown in Figure 2c clearly evidences the distribution of elements in the sample, confirming a high quantity of $\mathrm{ZnO}$ ( $\mathrm{Zn}$ and $\mathrm{O}$ atoms) in the center of the nanofibers, surrounded with a N, C and Zn-containing compound which corresponds to ZIF-8 material (See Figure S3: line scan). Even if sample observation was relatively tricky, the ZIF-8 layer grown on the $\mathrm{ZnO}$ surface was found to cover the entire fiber surface. The thickness of the covering layer was in the range $50-250 \mathrm{~nm}$. Some large ZIF-8 crystals (500 
$\mathrm{nm}$ in size) with very angular shapes were also detected on few nanowires. An encapsulation of a large majority of $\mathrm{ZnO} \mathrm{NWs}$ by the molecular sieving membrane (i.e. without nonselective preferential pathways) is a required condition for controlling the access of gas species to the $\mathrm{ZnO}$ sensing material and obtaining efficient sensor response improvements. Due to both small dimensions of the gas sensor support and extremely low quantity of the deposited ZnO@ZIF-8 NWs composite materials (thin layer of ZIF-8 covering ZnO NWs) it was not feasible to perform any direct measurement of their specific surface area. In parallel experiments with other types of supports providing much higher available surfaces (PolyAcryloNitrile fibrous mats), the specific surface area of ZnO@ZIF-8 materials, prepared by conversion of an ALD $\mathrm{ZnO}$ layer on PAN fibers, has been found to reach $\mathrm{S}_{\mathrm{BET}}=1760 \pm$ $260 \mathrm{~m}^{2} / \mathrm{g}$. Because of the negligible contribution of PAN mat and significantly low surface area of $\mathrm{ZnO}$ ALD layer $\left(\mathrm{S}_{\mathrm{BET}}(\mathrm{ZnO}) \sim 10 \mathrm{~m}^{2} / \mathrm{g}\right)$, the high $\mathrm{S}_{\mathrm{BET}}$ value of the composite system was principally attributed to ZIF-8 contribution. ${ }^{16}$ 

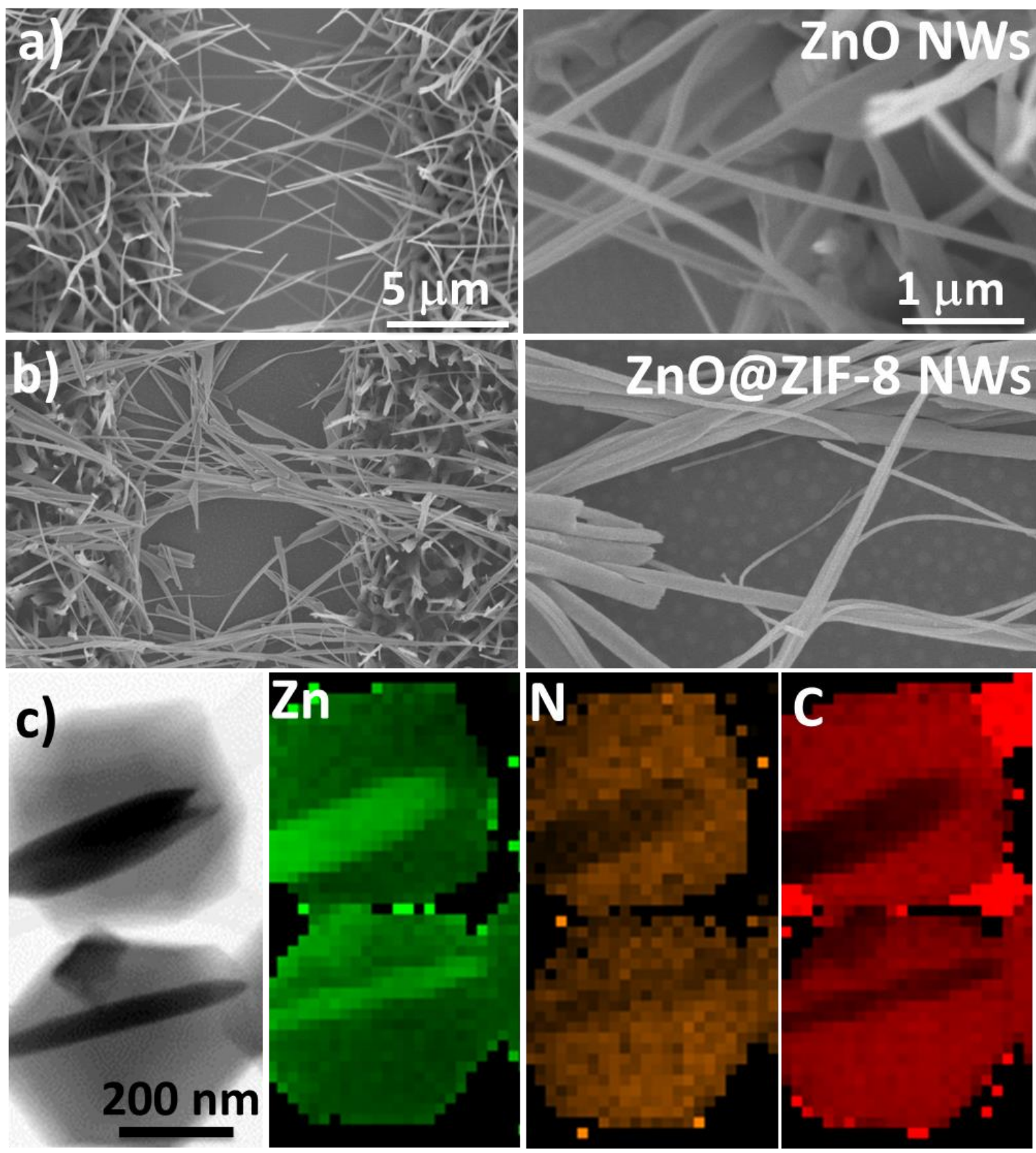

Figure 2. a) plane-view FESEM image of networked $\mathrm{ZnO}$ nanowires, b) $\mathrm{ZnO} @ \mathrm{ZIF}-8$ composite nanowires and c) TEM images of ZnO@ZIF-8 composite nanowires and the corresponding STEM/EDX cartography for Zn, $\mathrm{N}$ and C elements.

The dynamic resistance curves of the ZnO NWs and ZnO@ZIF-8 NWs were obtained for various kinds of reducing gases, such as $\mathrm{H}_{2}, \mathrm{C}_{6} \mathrm{H}_{6}$ and $\mathrm{C}_{7} \mathrm{H}_{8}$ with concentrations in the range 
of 10 to $50 \mathrm{ppm}$. Results are compared in Figure 3. For the pristine ZnO NWs, the typical ntype sensing behavior is observed; the sensor resistance decreases with the introduction of the tested reducing gases, whereas it reversibly recovers the original resistance value when the supply of the reducing gases is stopped and dry air is supplied. In ambient air, oxygen species adsorbed to the surface of the $\mathrm{ZnO} \mathrm{NWs}$ extract electrons from the $\mathrm{ZnO}$ conduction band, forming an electron-depletion layer underneath of the nanowire surface. ${ }^{17}$ This suppresses the conduction channel of the nanowire along the radial direction, determining the overall resistance of the pristine $\mathrm{ZnO}$ NWs sensor. The reducing gases supplied interact with the preadsorbed oxygen species, creating volatile molecules, thereby returning the captured electrons back to the conduction band of $\mathrm{ZnO}$. This thins the electron-depletion layer, namely, the radial modulation of the conduction channel takes place. This consequently decreases the sensor resistance.

In Figure 3, a dramatic change in sensor response can be observed in the presence of ZIF-8 membrane grown on the $\mathrm{ZnO}$ NWs surface. For $\mathrm{H}_{2}$ sensing characteristics (Figure 3a), the response values of the pristine $\mathrm{ZnO}$ NWs that correspond to 2.34, 2.47 and 2.62 for 10,30 and $50 \mathrm{ppm} \mathrm{H}_{2}$ respectively, are found to decrease to $1.17,1.34$ and 1.44 , respectively for the optimized ZnO@ZIF-8 NWs composite sensor. In sharp contrast, the responses of the composite ZnO@ZIF-8 NWs for $\mathrm{C}_{7} \mathrm{H}_{8}$ (Figure 3b) and $\mathrm{C}_{6} \mathrm{H}_{6}$ (Figure 3c) are almost vanished, approaching 1.0. Note that the response value of "1.0" means no resistance change before and after the gas supply, indicating zero gas sensing response. As expected and as a result of size exclusion effect by the small portal size of ZIF-8 cavities $(3.4 \AA)$ the molecular sieving capability of the ZIF-8 membrane layer prevents $\mathrm{C}_{7} \mathrm{H}_{8}$ and $\mathrm{C}_{6} \mathrm{H}_{6}$ gas molecules (kinetic diameters $5.92 \AA$ and $5.27 \AA$, respectively) from accessing the ZnO NWs surface, thus resulting in virtually zero gas sensing response. On the other hand, $\mathrm{H}_{2}$ molecules, featuring smaller kinetic diameter $(2.89 \AA)$, can diffuse easily through the ZIF-8 membrane network 
and can thus access the $\mathrm{ZnO}$ NWs surface, ensuring preservation of a significant $\mathrm{H}_{2}$ response. However, at the same time, the sensor sensitivity is limited by the diffusion of $\mathrm{H}_{2}$ through the ZIF-8 membrane network which controls the access of $\mathrm{H}_{2}$ to the $\mathrm{ZnO}$ NWs surface and thus its detection rate. The high adsorption capacity of MOF structures (concentration effect) is also expected to further contribute to increase the sensor response sensitivity towards the diffusing species. This finding clearly indicates the enhanced selective detectability of $\mathrm{H}_{2}$ when using the optimized ZnO@ZIF-8 composite NWs sensor. The thermal stability of ZnO@ZIF-8 composites has been first evaluated both by TGA analysis (Figure S4) and the in-situ X-ray thermodiffraction study (Figure S5), while the stability of ZnO@ZIF-8 NWs has been assessed directly during gas sensing experiments. The above analytical techniques confirmed an excellent material steadiness up to $400^{\circ} \mathrm{C}$, thus making it sufficiently stable for long-term gas sensing experiments performed at $300^{\circ} \mathrm{C}$. The sample was maintained at the operating temperature of $300^{\circ} \mathrm{C}$ for durations as long as $72 \mathrm{~h}$ and its $\mathrm{H}_{2}$-sensing properties were measured at different time intervals. The results are summarized in Figure S6. As evidenced, the response curves to 10,30 and $50 \mathrm{ppm}_{2}$ track well the supply and cutoff of $\mathrm{H}_{2}$ gas, even after $72 \mathrm{~h}$ at $300^{\circ} \mathrm{C}$. Such experiment demonstrates not only that the composite ZnO@ZIF-8 NWs sensor was very stable at the operating temperature of $300^{\circ} \mathrm{C}$, but was also excellent in response repeatability. Additionally, in Figure S7, the $\mathrm{H}_{2}$ sensing properties measured at $250^{\circ} \mathrm{C}$ of the composite ZnO@ZIF-8 NWs sensor are shown. As is evident, the sensor clearly tracks the presence of $\mathrm{H}_{2}$, demonstrating its stable sensing performance at that operating temperature. Moreover, it must be noted that in spite of the excellent $\mathrm{H}_{2}$ selectivity of the ZnO@ZIF-8 NWs sensor, its response remains quite low. In sensor applications, a low response might be amplified by a simple electrical circuit, although selectivity cannot. Selectivity is thus a more important sensor characteristic that needs to be as high as possible 
for real sensor applications. In this sense, the novel approach attempted in this study has a considerable significance.
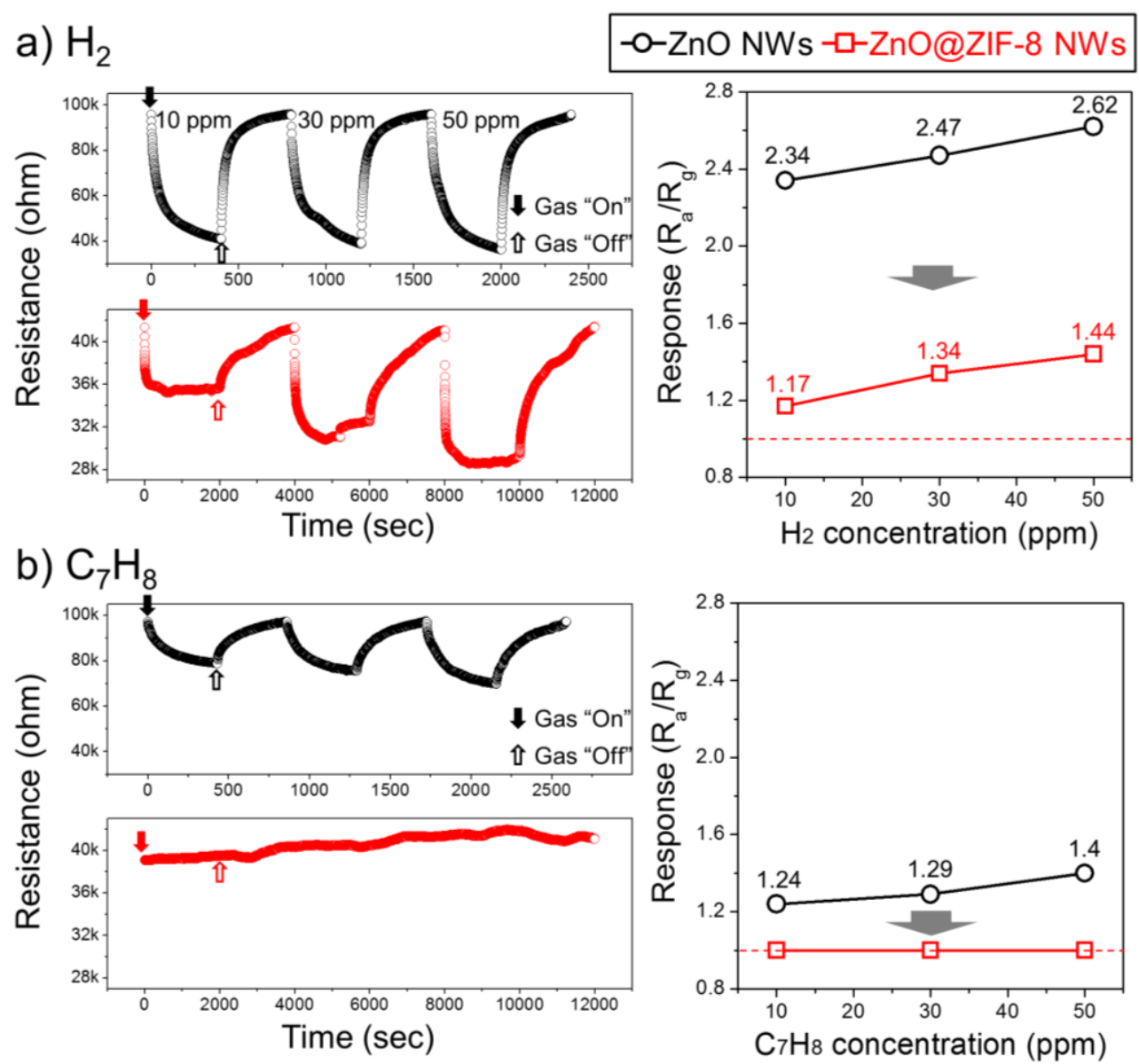

c) $\mathrm{C}_{6} \mathrm{H}_{6}$
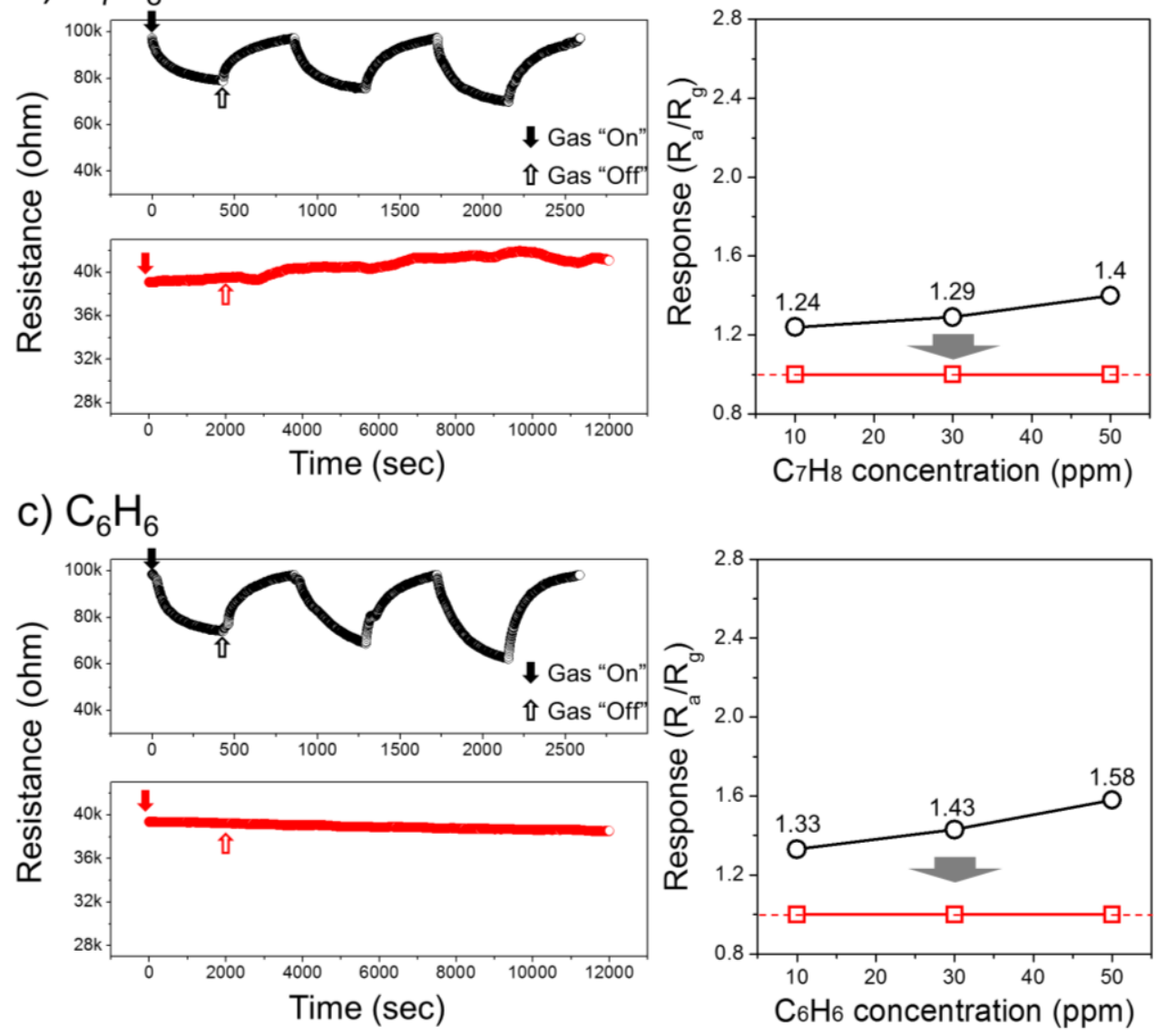

Figure 3: Responses of the pristine $\mathrm{ZnO}$ nanowires and $\mathrm{ZnO} @ \mathrm{ZIF}-8$ composite nanowires in contact with 10, 30 and 50 ppm single gas concentration: $\mathrm{H}_{2}(\mathrm{a}) ; \mathrm{C}_{7} \mathrm{H}_{8}$ (b) and $\mathrm{C}_{6} \mathrm{H}_{6}$ (c). 
In summary, we have established a very promising strategy for improving the selectivity of SMOx sensors with NWs morphology. This approach involves the preparation of an original design of the functional material based on the encapsulation of $\mathrm{ZnO}$ nanowires with a thin ZIF-8 selective nanomembrane exhibiting both high equivalent specific surface area and molecular sieving properties. The ZnO@ZIF-8 NWs sensors show greatly enhanced selectivity at $300^{\circ} \mathrm{C}$ for $\mathrm{H}_{2}$ over $\mathrm{C}_{7} \mathrm{H}_{8}$ and $\mathrm{C}_{6} \mathrm{H}_{6}$ in comparison to the pristine $\mathrm{ZnO}$ nanowires sensor.

This new approach is highly versatile because it can be used to prepare sensors in which the oxide composition $^{18}$ and derived molecular sieve (oxide conversion to different MOF families) ${ }^{16}$ can be tuned accurately in order to improve the selectivity of SMOx sensors to different gas mixtures. This strategy opens the door as well to the potential development of a large class of nanomaterials with more complex three-dimensional architectures, adapted for applications where either gas $^{19}$ or ion $^{20}$ selectivity is required such as biosensors, ${ }^{21}$ catalysts, ${ }^{22-23}$ photocatalysts, ${ }^{24}$ electrodes and membrane reactors.

ACKNOWLEDGEMENTS: This research was co-founded in France by both Campus France (grant No. 29888RC- Star 2013) and the Institut Européen des Membranes (exploratory project COMET-MOF- "Next Generation Membranes"- Internal IEM Call 2015). This study was also supported by the National Research Foundation of Korea (NRF) through a grant funded by the Korea government (MEST) (NRF-2013K1A3A1A21000149). The authors also acknowledge Eric Leroy (Institut de Chimie et des Matériaux Paris-Est) for HR-TEM observations. 
SUPPORTING INFORMATION. An experimental section (sensors synthesis, gas sensing measuremets), additional EDX measurement during SEM and TEM observation, XRD, XPS, TGA analyses and gas sensing at $250^{\circ} \mathrm{C}$ and long-term stability are supplied as Supporting Information.

\section{REFERENCES}

1. Du, X. Understanding and Optimization of Gas Sensors Based on Metal Oxide Semiconductors. CU-Boulder 2007, 272 pages; 3284441

2. Kumar, A.; Kim, H.; Hancke, G. P., Environmental Monitoring Systems: A Review. IEEE Sens. J. 2013, 13, 1329-1339.

3. Di Natale, C.; Paolesse, R.; Martinelli, E.; Capuano, R., Solid-State Gas Sensors for Breath Analysis: A Review. Anal. Chim. Acta 2014, 824, 1-17.

4. Ponzoni, A.; Comini, E.; Concina, I.; Ferroni, M.; Falasconi, M.; Gobbi, E.; Sberveglieri, V.; Sberveglieri, G., Nanostructured Metal Oxide Gas Sensors, a Survey of Applications Carried out at Sensor Lab, Brescia (Italy) in the Security and Food Quality Fields. Sensors 2012, 12, 17023.

5. Korotcenkov, G., Metal Oxides for Solid-State Gas Sensors: What Determines Our Choice? Mater. Sci. Eng. B 2007, 139, 1-23.

6. Liu, X.; Cheng, S.; Liu, H.; Hu, S.; Zhang, D.; Ning, H., A Survey on Gas Sensing Technology. Sensors 2012, 12, 9635.

7. Kim, I.-D.; Rothschild, A.; Tuller, H. L., Advances and New Directions in GasSensing Devices. Acta Mater. 2013, 61, 974-1000.

8. Korotcenkov, G.; Cho, B. K., Engineering Approaches for the Improvement of Conductometric Gas Sensor Parameters: Part 1. Improvement of Sensor Sensitivity and Selectivity (Short Survey). Sens. Actuators, B 2013, 188, 709-728.

9. Korotcenkov, G.; Cho, B. K., Engineering Approaches to Improvement of Conductometric Gas Sensor Parameters. Part 2: Decrease of Dissipated (Consumable) Power and Improvement Stability and Reliability. Sens. Actuators, B 2014, 198, 316-341.

10. Zhang, J.; Liu, X.; Neri, G.; Pinna, N., Nanostructured Materials for RoomTemperature Gas Sensors. Adv. Mater. 2016, 28, 795-831.

11. Renard, L.; Elhamzaoui, H.; Jousseaume, B.; Toupance, T.; Laurent, G.; Ribot, F.; Saadaoui, H.; Brötz, J.; Fuess, H.; Riedeld, R.; Gurlo, A., Low-Temperature $\mathrm{H}_{2}$ Sensing in Self-Assembled Organotin Thin Films. Chem. Commun. 2011, 47, 1464-1466.

12. Renard, L.; Brötz, J.; Fuess, H.; Gurlo, A.; Riedel, R.; Toupance, T., Hybrid Organotin and Tin Oxide-Based Thin Films Processed from Alkynylorganotins: Synthesis, Characterization, and Gas Sensing Properties. ACS Appl. Mater. Interfaces 2014, 6, 1709317101.

13. Drobek, M.; Bechelany, M.; Vallicari, C.; Abou Chaaya, A.; Charmette, C.; SalvadorLevehang, C.; Miele, P.; Julbe, A., An Innovative Approach for the Preparation of Confined Zif-8 Membranes by Conversion of Zno Ald Layers. J. Membr. Sci. 2015, 475, 39-46.

14. Liu, D.; Lu, K.; Poon, C.; Lin, W., Metal-Organic Frameworks as Sensory Materials and Imaging Agents. Inorg. Chem. 2014, 53, 1916-1924. 
15. Lu, G.; Hupp, J. T., Metal-Organic Frameworks as Sensors: A Zif-8 Based Fabry-Pérot Device as a Selective Sensor for Chemical Vapors and Gases. J. Am. Chem. Soc. 2010, 132, 7832-7833.

16. Bechelany, M.; Drobek, M.; Vallicari, C.; Abou Chaaya, A.; Julbe, A.; Miele, P., Highly Crystalline Mof-Based Materials Grown on Electrospun Nanofibers. Nanoscale 2015, 7, 5794-5802.

17. Katoch, A.; Kim, J.-H.; Kwon, Y. J.; Kim, H. W.; Kim, S. S., Bifunctional Sensing Mechanism of $\mathrm{SnO}_{2}-\mathrm{ZnO}$ Composite Nanofibers for Drastically Enhancing the Sensing Behavior in $\mathrm{H}_{2}$ Gas. ACS Appl. Mater. Interfaces 2015, 7, 11351-11358.

18. Marichy, C.; Bechelany, M.; Pinna, N., Atomic Layer Deposition of Nanostructured Materials for Energy and Environmental Applications. Adv. Mater. 2012, 24, 1017-1032.

19. Xu, X.; Zhang, Z.; Wang, X., Well-Defined Metal-Organic-Framework Hollow Nanostructures for Catalytic Reactions Involving Gases. Adv. Mater. 2015, 27, 5365-5371.

20. Kreno, L. E.; Leong, K.; Farha, O. K.; Allendorf, M.; Van Duyne, R. P.; Hupp, J. T., Metal-Organic Framework Materials as Chemical Sensors. Chem. Rev. 2012, 112, 11051125.

21. Wu, X.-Q.; Ma, J.-G.; Li, H.; Chen, D.-M.; Gu, W.; Yang, G.-M.; Cheng, P., MetalOrganic Framework Biosensor with High Stability and Selectivity in a Bio-Mimic Environment. Chem. Commun. 2015, 51, 9161-9164.

22. Liu, Y.; Tang, Z., Multifunctional Nanoparticle@MOF Core-Shell Nanostructures. Adv. Mater. 2013, 25, 5819-5825.

23. Chen, L.; Chen, H.; Luque, R.; Li, Y., Metal-Organic Framework Encapsulated Pd Nanoparticles: Towards Advanced Heterogeneous Catalysts. Chem. Sci. 2014, 5, 3708-3714.

24. Zhan, W.-w.; Kuang, Q.; Zhou, J.-Z.; Kong, X.-j.; Xie, Z.-X.; Zheng, L.-s., Semiconductor@Metal-Organic Framework Core-Shell Heterostructures: A Case of Zno@Zif-8 Nanorods with Selective Photoelectrochemical Response. J. Am. Chem. Soc. 2013, 135, 1926-1933. 
TABLE OF CONTENTS GRAPHIC

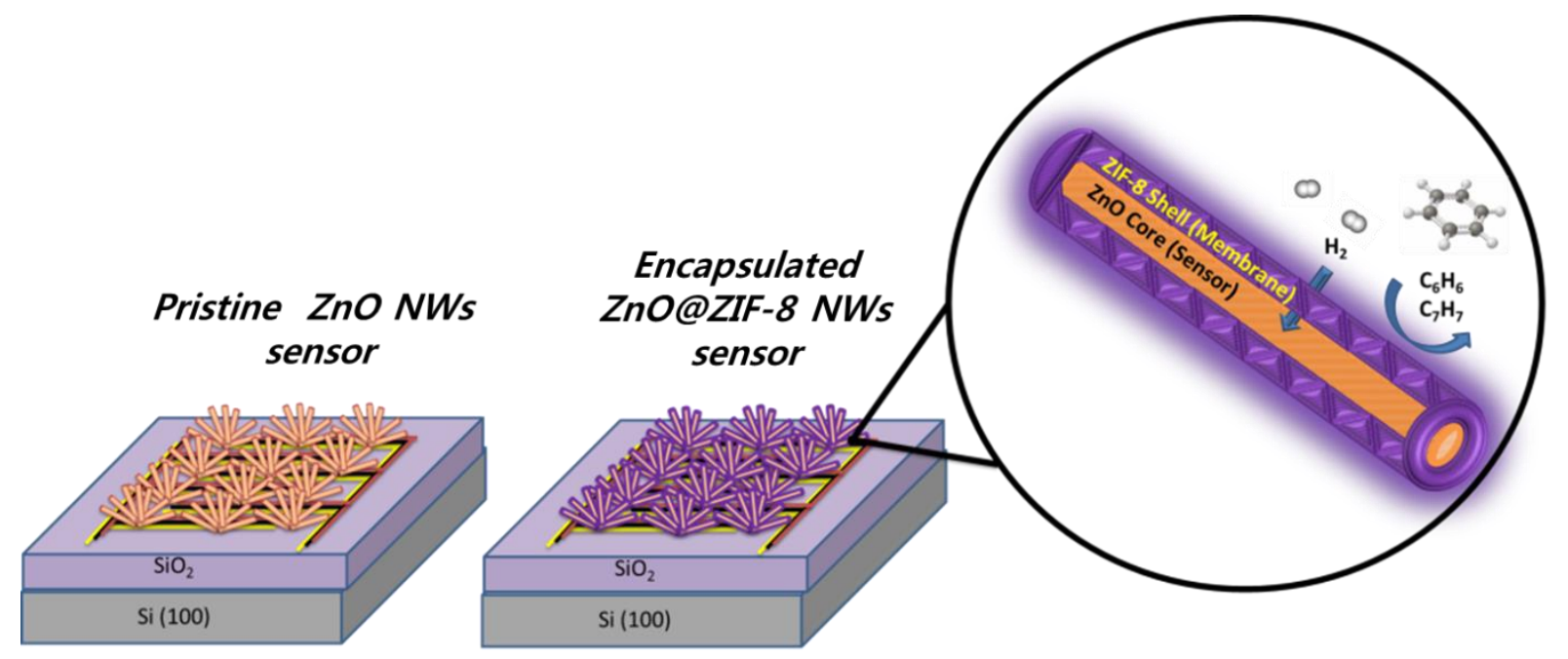

